\title{
Lexical Modulation without Concepts
}

\author{
Nicholas ALLOTT ${ }^{1} \&$ Mark TEXTOR $^{2}$
}

\begin{abstract}
We argue against the dominant view in the literature that concepts (understood as the standing meanings of general terms) are modulated in lexical modulation. We also argue against the alternative view that 'grab bags' of information that don't determine extensions are the starting point for lexical modulation. In response to the problems with these views we outline a new model for lexical modulation that dispenses with the assumption that there is a standing meaning of a general term that is modified in the cases under consideration. In applying general terms we intend to conform with our linguistic ancestors and in doing so we take facts about the referents of these terms for granted. In cases of lexical modulation we become aware of facts we took for granted and we need to change the facts we take for granted in order to see ourselves as continuing in a practice. These changes result in utterances of the general term referring to different properties. In general, concepts are neither the starting point for lexical modulation nor the standing meanings of words.
\end{abstract}

\section{Introduction}

Lexical modulation is much discussed in the recent literature on lexical pragmatics. The basic idea is that words have context-independent standing meanings that are 'modulated' when these words are uttered for specific communicative purposes. For instance, when you answer my question 'Who can help me carry the piano and cook dinner tonight?' by saying 'John is a saint', your utterance of 'saint' does not contribute to the proposition expressed the context-independent standing meaning of 'saint', the concept of a person recognized for his holiness by the church. The standing meaning of 'saint' is modulated and an ad hoc concept constructed. The ad hoc concept is part of the proposition expressed by an utterance: it is the meaning of a particular utterance of the word. Uses of words such as 'green', 'cut', 'saint' therefore express occasion-specific meanings.

In describing lexical modulation, linguists and philosophers have standardly made three assumptions (Wilson \& Carston, 2007; Recanati, 2012):

(A1) A word has a standing, context-independent meaning determined by linguistic

\footnotetext{
${ }^{1}$ Department of Literature, Area Studies and European Languages, University of Oslo, P.O. Box 1003, Blindern, 0315 Oslo, Norway; email: nicholas.allott@gmail.com

${ }^{2}$ Department of Philosophy, King's College London, 160 Strand, London WC2R 2LS, UK; email: mark.textor@kcl.ac.uk
} 
conventions/encoding;

(A2) The standing meaning is a concept that has an extension;

(A3) Utterances communicate structured propositions to which the utterance of a word contributes an ad hoc concept.

It is generally assumed that words have stable and context-invariant 'standing' meanings. In a further step these standing meanings are identified with concepts - although the consensus here is shifting ${ }^{3}$. Concepts are psychological representations of properties. (See Wilson \& Sperber 2002, $607 \mathrm{fn}$. 9) The extension of a concept is the set of all and only those things that have the property. In the limiting case, the extension of a concept is the empty set. Concepts are activated when one uses a word with understanding. Hence, they are conceived of as memory addresses that give access to information about a property/kind.

The most developed version of the account, due to Sperber \& Wilson and Carston, adds the following:

(A4) Pragmatic lexical adjustment takes one from the standing meaning to a non-lexicalised concept whose extension is a sub-, super or combination of sub/superset of the extension of the lexicalized concept. (narrowing/ broadening). (The earliest publications of this view were Carston, 1997; Sperber \& Wilson, 1998. Wilson \& Carston, 2007, is a developed statement).

In addition, both Recanati and the relevance theorists add:

(A5) The concepts encoded (per A2) by words have associated stores of encyclopaedic information; the accessibility of this information is context-sensitive; and ad hoc concepts are constructed from this information, starting with the information that is accessible in the

\footnotetext{
${ }^{3}$ It is not clear what Recanati's settled view is. In his $(2004$, ch. 9) he explores the view that words have 'semantic potentials' rather than standing for concepts. This view rejects (A2). But in his (2012) he also offers a classical, definitional theory of word meaning, accepting (A2): see discussion of 'cut' below. Carston seems to have changed her mind about the issue between her $(2010, \S 4)$ which refers repeatedly to "lexically encoded concepts" and her (2012), where she argues that the encoded meanings of words are not concepts.
} 
context. $^{4}$

In this paper we will not discuss (A3) and (A4). ${ }^{5}$ In particular, we do not want (or need) to make general claims about the role of concepts in cognition here. We will focus on assessing the assumptions (A1), (A2) and (A5) of the standard theory and argue that neither context-independent concepts, whether complex or atomic, nor Kaplanian characters nor non-semantic abilities to re-enact situations are suitable standing meanings of words. Our positive suggestion draws on causal theories of competence that identify linguistic competence with an acquired social trait: one is competent with a word if, and only if, one is sufficiently inducted into a practice of its use. This view, we will propose, helps us to understand lexical modulation better than the standard theory and its descendants.

\section{Problems for the Standard Theory}

According to the standard account, pragmatic lexical modulation takes the concept expressed by a word as input and yields as output an ad hoc concept that is narrowed or broadened relative to the lexicalized concept (or, on some occasions, both narrowed and broadened). Lexical modulation affects the proposition expressed (aka 'what is said') and this helps explain the fact that different utterances of a sentence may convey different speaker-intended implications. Take example (1):

(1) Mary: Who can help me move this piano?

Paul: John is a saint.

Grice and early linguistic pragmatics treated such cases as ones in which the standing linguistic meaning is not asserted, and what the speaker actually intends to communicate is a related implicature. Many contemporary theorists disagree, arguing that lexical modulation contributes to

\footnotetext{
${ }^{4}$ Cf. Sperber \& Wilson on interpretations of 'soldier' (2002, 19-20); Recanati (2004, ch. 2, § 2.3). According to Recanati, the ad hoc concept is simply whatever is the most accessible one in the context, while in relevance theory the most accessible interpretation is a candidate to be the correct interpretation but may be rejected, in which case another interpretation is constructed and tested etc. ${ }^{5}$ For a criticism of (A4) see Allott \& Textor (2012). We are agnostic about A3. Nothing we say here is intended to deny that concepts play important roles in (inter alia) inference and categorization. Our main claims about concepts are the narrower ones that concepts are not the standing meanings of words nor the starting point for lexical modulation.
} 
truth-conditional or 'near-side' pragmatics. ${ }^{6}$

Evidence that the ad hoc concept 'gets into' what the speaker asserts (or 'says' in Grice's special sense) comes from the intuition that logical operators such as negation can target the occasion-specific sense, as in the following rejoinder to Paul's remark in $(2)^{7}$ :

(2) No, he's not a saint: he only pretends to be helpful and self-sacrificing when he thinks it'll make him look good.

Another argument comes from neologisms, such as the ones in (3):

(3) a. The boy porched the newspaper.

b. She wristed the ball over the net. (Wilson \& Carston, 2007, 237)

Wilson and Carston argue that these newly coined verbs porch and wrist can have no encoded meaning, and "thus, if the ad hoc concepts PORCH*, WRIST* [...] do not contribute to the proposition expressed or asserted by these utterances, there is no proposition expressed or asserted at all.” (Wilson \& Carston, 2007, 237)

Consider a further type of example, utterances of apparently contradictory sentences, such as the one in (4):

(4) He was upset but he wasn't upset. [Said by 'Kato' Kaelin of O.J. Simpson in the famous trial.] (Carston, 2002a, 137; 2002b, 334)

Intuitively, the thought that this sentence was used to express was not a contradiction. As Carston analyses it, "[t]he two instances of the word 'upset' were interpreted as communicating two different concepts of upsetness", and the second one (at least) is modulated, such that it "carries certain implications (e.g. that he was in a murdering state of mind) that the first one does not, implications whose applicability to [Simpson] the witness is denying." (Carston 2002a, 137).

\footnotetext{
${ }^{6}$ The label 'truth-conditional pragmatics' is from Recanati (1993); 'near-side pragmatics' is from Korta \& Perry (2006).

${ }^{7}$ See Cohen, 1971; Recanati, 1989.
} 
Now assumptions (A1) and (A2) of the standard model are problematic. Many linguists and philosophers of language have come round to the view that linguistic competence cannot require knowledge of concepts. Why?

First, if we take concepts to be specified by definitions, most words seem not to express concepts. It is widely agreed that hardly any useful word can be defined. ${ }^{8}$

Second, what is the standing meaning of 'cut' that is modulated (or - if some uses are now lexicalised - was modulated in their first use) in examples like those in (5a-e) (after Searle, 1980)?

(5) a. John cut the cake.

b. John cut the lawn.

c. John cut his hair.

d. John cut his finger.

e. John cut taxes.

The classical, definitional, view is that each (lexical) word stands for a concept, where a concept determines (or is) a list of individually necessary and jointly sufficient conditions. For example, Recanati's preferred specification of the standing meaning of 'cut' is "something like EFFECT A LINEAR SEPARATION AFFECTING THE INTEGRITY OF (SOME OBJECT) BY MEANS OF AN EDGED INSTRUMENT.” (Recanati 2012, 185). Here the problem of providing a conceptual standing meaning has been offloaded to 'effect', 'linear', 'separation' etc., but these words (or features) used to specify the standing meaning of 'cut' suffer from the same problems as 'cut'. Consider the following examples:

(6) a. Obi-Wan cut the cake with his lightsabre.

b. Fred cut the gruyère with the wire.

Both seem perfectly felicitous: these are instances of cutting. However a lightsabre has no edge, and cheese wire need not - it could be circular in cross-section. So Recanati's definition is not satisfied.

One might want to say an occasion-specific sense of 'EDGED' is in play, and that lightsabre and cheese wire have an edge in this occasion-specific sense. If this is right, then 'EDGED' in the

\footnotetext{
${ }^{8}$ See Fodor et al., 1980; Fodor 1998, chapt. 3 and 4.
} 
definition of 'cut' seems not to refer to a fixed property. ${ }^{9}$

Similar problems can be raised for the other components of the definition. One can cut a block of ice with a hot wire such that its integrity is not permanently affected, since the parts immediately melt together (cf. example 7). This raises the question: which properties do 'affect' and 'integrity' etc. refer to?

(7) John: Have you cut the block of ice?

Jim: Yes.

John: But there are no separate parts.

Jim: But I have cut it. The wire went right through.

To summarize our objection: definitional specifications of meaning such as Recanati's only work if the meaning of the words (or semantic features) in the specification are adapted to specific occasions. It seems impossible that all such specific occasions could be foreseen and incorporated into the definition. So the meanings of the words (or features) in the specification must themselves be contextsensitive.

A response to the first problem mentioned above is that lexical words encode atomic concepts, that is concepts which do not decompose and are not in general definable. Can such atomic concepts be the standing meaning of lexical words? A challenge to this view comes from what have become known as 'Travis cases' after their inventor. Consider the following examples:

(8) a. This apple is green.

b. This glass is green.

The sentence in (8a) could be used to say something true of an apple that is green skinned. But it could also be truthfully used to report that an apple has an unusual interior colour. What then is the concept that 'green' encodes: a-certain-colour-on-the-outside or a-certain-colour-on-the-inside? Perhaps rather a property that is neutral between these. The example in $(8 b)$ seems to show that it will also have to be neutral as to whether the perceived colour is due to the reflection or the transmission

\footnotetext{
${ }^{9}$ Our point here is related to what Bezuidenhout $(2002,124)$ calls 'higher-level' occasion-sensitivity, drawing on Travis (2000).
} 
of light. Similarly, the examples in (9) (cf. Chomsky 2000, 16-17) raise the question: what is the concept encoded by 'book' - a type of physical object with printed pages or a collection of intellectual content?

(9) a. This book weighs twelve pounds.

b. This book, which is full of important ideas, has been published in paperback and hardback.

What could be the atomic concept under which both intellectual contents as well as physical objects fall?

One alternative view is that one of the concepts is basic and the other is always derived from it. But this seems ad hoc unless some independent evidence can be produced. Another alternative view is that 'book' is lexically ambiguous: one string of speech sounds links to two distinct concepts. However this fails to distinguish 'book', whose senses are clearly related, from genuine cases of homonymy such as river 'bank' and financial 'bank'. (See Pietroski, 2017, for more on this last point.) What is more, it seems that 'green' and 'cut' (and many other words) would have to be multiple homonyms linked to indefinitely many concepts.

A further option is developed by Wilson and Carston 2007. They propose a unified account of lexical modulation that builds on (A5). According to them, atomic concepts provide access to encyclopaedic information about the objects in their extension. All cases of lexical modulation consist in selecting encyclopaedic properties. In effect, all the work that was supposed to be done by concepts is now done by encyclopaedic information that is accessed via concepts, which are seen as mental files locked to properties. Is this a viable proposal?

In order to answer this question we need to look more closely at the notion of encyclopaedic information. For Wilson and Carston (as they say in a footnote: p. 256, n. 22) 'encyclopaedic property' is a shorthand for proposition that has an encyclopaedic property as a constituent: 'each property should be seen as a constituent of a complete proposition' (ibid). These propositions serve as premises from which conclusions are drawn that either satisfy expectations of relevance or do not. If these expectations are met, the propositions from which the conclusions are drawn count as expressed by the utterance ${ }^{10}$. Prima facie, this works in some cases. For instance, in the ice cutting case, the encyclopaedic property of separation may be activated at the cost of the permanence property. But the

\footnotetext{
${ }^{10}$ In the terminology of relevance theory, they are 'implicated premises', for obvious reasons. See Sperber and Wilson 1986, 194-195; Allott 2013, 77-8.
} 
assumption that we start from propositions specifying encyclopaedic information is problematic. ${ }^{11}$ No concept seems to determine an extension, so how could propositions that contain concepts of encyclopaedic properties serve as starting points in modulation? To make the problem clear we can go back to our ice cutting example. There are situations in which we need to modify the permanence concept that may be assessable from the cutting concept. If Wilson and Carston are right about modulation, we need to make inferences from propositions that contain concepts of encyclopaedic features assessable from our concept of cutting to arrive at the occasion specific ad hoc concept expressed by 'cut'. But each of the concepts of encyclopaedic properties invoked by 'to cut' might itself need modulation to be applicable to the case under consideration. Hence, we need even more propositions and concepts to make further inferences and so on. In principle, we are embarked on a never-ending process.

\section{Problems for the Character View of Standing Meaning}

In view of such problems one may hold that standing meaning should, instead of a concept, be something that could be neutral between different concepts that use of the words expresses. One such proposal is that the standing meaning of a lexical word is a Kaplanian character. For example, Szabó (2001); Rothschild and Segal (2009); Kennedy and McNally (2010); and Hansen (2011), propose accounts of colour terms along these lines. More generally, Stanley has claimed that 'all truthconditional effects of extra-linguistic context can be traced to [linguistic] logical form' $(2000,391)$.

On such accounts, the standing meaning of a word determines (or is) a function which takes a context as argument, and returns a semantic value which is contributed in the normal compositional fashion to the proposition expressed by the sentence used in context. In the examples in (5) the semantic value would be a mode of cutting. This view assimilates the semantics of lexical words to that of pronouns and other obvious indexicals and perhaps to degree-adjectives like 'tall'.

Here are two arguments against the view.

\footnotetext{
${ }^{11}$ We assume here that Wilson and Carston don't really hold that propositions 'contain' properties as constituents, but that the propositions under consideration contain concepts or at least some kind of mental representation of encyclopaedic properties. For while a view of propositions as truth-apt complexes of particulars and properties is defended in the literature by Neo-Russellians, it faces serious problems and is not in the spirit of Wilson and Carston's general approach. If properties are constituents of propositions, the sentences 'This animal is a groundhog' and 'This animal is a woodchuck' express the same proposition, since being a groundhog is the same property as being a woodchuck. But the inferences we are prepared to draw when accepting the sentences are different. Hence, Neo-Russellian propositions are not well-suited to be the premises of our inferences.
} 
First, the kinds of enrichment of meaning that may occur are so various that many variables or indices would be needed (Bezuidenhout 2002, 114; Wilson \& Sperber, 2002; Pietroski, 2010). Wilson and Sperber consider the suggestion that the standing meaning of 'have eaten' might be a character which requires a contextually-supplied time span and object of eating to express a content. But as the following examples demonstrate, the outcome of lexical modulation is not constrained only to providing a time and object of eating, but can also specify place or manner of eating. (Plausible pragmatic enrichment is indicated by the material in square brackets.)

(10) a. I've often been to their parties, but I've never eaten anything [there].

b. I must wash my hands: I've eaten [using my hands, rather than, say, being spoon-fed]. (Wilson \& Sperber 2002, 611 - their examples 28, 29)

Thus 'have eaten' would need four variables or slots, of which three (object, place and manner) presumably belong to 'eat'. With enough ingenuity, examples can be constructed showing that enrichment can have still other dimensions. Sperber and Wilson argue that this is a reductio of the character/hidden variable account of context-sensitivity. Similarly, Paul Pietroski writes:

If meanings are instructions to build concepts, we can grant that I-expressions have some covert indices, but not enough to track all the ways in which truth can depend upon context. $(2010,267)^{12}$

To summarize our argument here: the proposal that the standing meanings of words are contextindependent characters is implausible in the face of examples that seem to show that lexical modulation can introduce new arguments. One could then claim that a lexical item in general encodes several different characters with different arguments, but this runs into the problems noted above for the view that they encode multiple concepts: it fails to distinguish polysemy from homonymy; and it in effect proposes open-endedly multiple ambiguity, which seems ad hoc.

Secondly, Bezuidenhout, (2002, 113-4) and Collins (2007) argue against 'hidden indexical' approaches to semantics that they are $a d$ hoc: there is no independent evidence - e.g. from syntax for the variables or indices that they postulate. Worse, the syntactic positions that these elements

\footnotetext{
${ }^{12}$ By 'I-expression' Pietroski means constituent of a natural language, such as a word, phrase or sentence, seen as a mental entity.
} 
would need to occupy are impossible according to contemporary syntactic theory, so "if recent generative theory is correct, Stanley's account is incorrect, or at least lacks the support he claims for it, for there is too little syntax." (Collins 2007, 826, his emphasis)

Where does this leave us? Lexical words seem to encode neither concepts nor Kaplanian characters. In the next section we will review varieties of lexical modulation that show the full breadth of the phenomenon. The examples considered will strengthen our case against the standard theory and prepare our criticism of a different, non-standard response.

\section{The Grammatical Flexibility of Lexical Modulation}

Words can move across syntactic categories in English and many other languages. ${ }^{13}$ For instance, 'cut' and 'stop' occur as nouns as well as verbs; 'chicken' as a sortal predicate and a mass term. We can also move in lexical modulation from, for instance, a noun and form 'on the fly' an ad hoc concept for an activity. Consider the examples (3a) and (3b) above, where 'porch' and 'wrist' are used as verbs. As we noted, Wilson and Carston argue that these novel verbs, coined for experimental work, cannot have had encoded meanings for the experimental participants. This seems correct. Here, the problem is that the concept encoded by the noun 'porch' would be the concept of an entity, while the ad hoc concept made up by the participants for the verb 'porch' would be that of an activity. It is difficult to see how the ad hoc concept can be a concept that subsumes a sub- or superset of the extension of the concept which is the supposed to be the standing meaning of (the noun) 'porch'. Nonetheless it seems attractive to see this as a case of lexical modulation in which one adapts a concept for an occasion.

Let us strengthen this point with a further example. Consider the examples in (11), which show that 'down', normally a preposition ${ }^{14}$, can be used as verb, noun and adjective (Brinton \& Traugott 2005, 38):

(11) a. Put the book down!

b. Down your drink.

c. He has a down on her. / Marc Trestman takes heat for missed field goal on second down.

d. I'm having a down day.

Presumably for most speakers at least some of these are derived on the fly from the preposition 'down', while some have become lexicalised in certain populations. For our purposes it does not

\footnotetext{
${ }^{13}$ See Rayo 2013, 673. See also Carston 2012, 614-5, 621.

${ }^{14}$ See Huddleston \& Pullum 2002, ch. 7; Pullum, 2013.
} 
matter which is which, since lexicalisation presupposes that there was an occasion in the past when the modulation was genuinely novel. This is because it seems natural to treat historical lexical semantic change as the gradual habituation and eventual fossilization of repeated pragmatic inferences, as has been suggested by linguists of several different theoretical persuasions (Lyons, 1977; Traugott \& König, 1991; Sperber \& Wilson, 1998; Traugott \& Dasher, 2002; Wilson \& Carston, 2007). Assuming this is correct, there must have been occasions on which examples like (11b, c and d) resulted from on-the-fly modulation of the preposition 'down'. This presents the standard view with a difficult problem: what could the DOWN concept be such that it can have all of the applications in (11)?

\section{Non-Semantic Standing Meaning and Lexical Modulation}

The conclusion of section 2 was that neither concepts (whether atomic or decomposable) nor Kaplanian characters are the standing meanings of predicate terms. There simply seems to be no good way to think of the standing meaning of 'book' ('cut') such that it is (i) a concept - whether atomic or not - that (ii) has as its extension all the things which can truly to be said to be books (events of cutting).

One response takes the source of this problem to be the assumption (A2). If one gives it up, one no longer needs to find a concept that is the basis of all uses of a word. A non-semantic representation may serve as standing meaning precisely because it does not determine an extension/property. For example, the verb 'to stop' and the noun 'stop' cannot express the same concept. Yet, they can 'come with' the same non-semantic representation. In the literature one can find three main versions of the idea that to know a word is not to grasp a concept. ${ }^{15}$

First, Barsalou has developed a theory of representation in which concepts are replaced by acquired abilities to simulate situations in ways that are specifically 'tailored' to purposes. (See Barsalou et al. 2008, 251.) Here is a rough outline and a telling example. After encounters with objects falling under a category we form a multimodal representation of members of the category that allows us to simulate encounters with members of the category. When activated in a context, the 'simulator' simulates some but not all of its content, the simulation or situated conceptualization:

For example, one situated conceptualization for [CAT] might support interacting with a playful kitten, whereas others might support interacting with a mean tom cat, or with a purring house cat. In this view, the concept for [CAT] is not a detached global description of

\footnotetext{
${ }^{15}$ See Bezuidenhout 2002, $115 \mathrm{ff}$. for discussion of some other non-semantic theories of lexical competence; also Carston 2012, §§3-4.
} 
the category. Instead, the concept is the skill or ability to produce a wide variety of situated conceptualizations that support goal achievement in specific contexts. (Barsalou 2005, 626, our emphasis.)

It seems wrong to say that the concept is the skill or ability to produce situated conceptualisations. An ability to simulate 'cat-involving' encounters is not a concept: it has no extension, is not a constituent of thoughts etc. We take it that Barsalou rather means that in explanations of human abilities one ought to replace concepts with simulators. This seems to be a step in the right direction. While a single atomic concept that purports to be of one kind of thing cannot be a concept of physical object, intellectual contents etc., one and the same ability may ground re-enactments of situations that involve all of these things. In order to imagine writing a book or buying a book, it might be enough to have had bought books, read books etc. and to re-enact these episodes.

Barsalou's replacement for concepts suggests a model for lexical modulation. It is the ability one brings to different contexts of utterance. The modulated meanings are the simulations that are activated when one has identified the linguistic form that belongs to a phonetically/form individuated word in a particular context. (See Barsalou et al. 2008, 250.) Only particular uses of words that activate simulations have 'meaning', the simulations provide the meaning. (ibid., 251.)

Does this view help us to understand lexical modulation? Consider cross-grammatical lexical modulation. Even if you have only heard 'swim' used as a verb, you may able to grasp what someone says in uttering (12):

(12) That was a long swim.

On Barsalou's model, the use of the verb 'to swim' activates the simulator for swimming activities. The step from simulating these activities to coming to understand that the result of such an activity is under consideration is not explained by the simulator. The crucial work is done by a further mechanism not covered by Barsalou.

More importantly, the question is how we should think of situated conceptualisations. Do I simulate (a) interacting with a cat that is nice or (b) interacting with Tommy the cat I owned some years ago? Option (b) seems phenomenologically implausible. Often we have no particular cat in mind when assessing what someone said about cats. Option (a) therefore seems the better bet. But then we have re-introduced the problem we want to avoid. Don't I need a general representation of a cat to simulate a cat in my home? If so, we can again ask how there could be such a thing that covers all the diverse applications we want and can make of 'cat'. 
Second, Rayo proposes that the standing meaning of a word is a 'grab bag' (see Rayo 2013, 648), that is, a possibly heterogeneous collection of mental items, such as images, memories and encyclopaedic information. Grab bags are not the right kind of thing to determine an extension/reference, as Rayo notes:

[I]t is not even clear what it would mean to say that an image, some encyclopaedic entries and a few memories determine a referent. (Rayo 2013, 657)

The standard view assumes that in lexical modulation one moves from a concept with one extension to a concept with a different one. We have seen that modulation across grammatical categories (noun to verb, sortal to mass noun) is a problem for this view. Rayo takes the grammatical versatility of words to speak in favour of the grab bag model:

[T]here is no need to use different grab bags for different grammatical categories. A mental image that evokes obstruction, for example, can be used to render salient the action of closing a valve when interpreting an assertion of 'she stopped the flow of oxygen', and to render salient a particular knob on a pipe organ when interpreting an assertion of 'she moved the stops to control the air-flow into her organ'. (Rayo 2013, 673).

A speaker who utters 'She stopped the flow of oxygen' and, on a different occasion, 'She moved the stops to control the air-flow into her organ' trusts (i) that she and her audience have similar memory images associated with 'stop' and (ii) that one and the same memory image can make an action/activity as well as a part of an object salient. Hence, one and the same grab bag suffices to sustain the formation of different $a d$ hoc concepts corresponding to different kinds of grammatical categories.

But what are the representations that bring to mind obstructions of various kinds? We think there is a dilemma here similar to the one faced by Barsalou. If the representations are memory images of particular obstructing events or objects, this seems a rather risky empirical hypothesis. Which particular obstruction that you encountered in the past do you think of when you understand the command 'She stopped the flow of oxygen'? However, if we think that the obstruction which comes to mind is the representation of a type of event or situation, we have simply substituted the problem of context-independent word meanings with the problem of general, occasion-independent mental representations of obstructions. Which mental image can be used to bring to mind activities such as closing a valve, halting a car and objects such as a knob on a pipe organ such that 'stop' construed as 
a verb and a noun applies to them? A mental image is open to many interpretations and can render radically different things salient. If lexical modulation consisted in the activation of such images, it would remain unclear how we ever would arrive at a particular truth-evaluable content.

The third non-semantic account of word meaning is Pietroski's view that words encode instructions to fetch concepts $(2010 ; 2017)$. What concept is fetched may depend on the other words in the sentence, the context, the communicative needs of the situation and so on. This seems promising, since it avoids the problems that bedevil conceptual theories of word meaning, and explains how one word can be used to express different concepts. However, as Pietroski has developed the theory, a lexical item only contributes an instruction to fetch a pre-existing concept; concept building comes later, when these concepts are combined to make the thought conveyed by the use of a sentence. This is because Pietroski is only concerned with cases of stable polysemy, such as the material and intellectual senses of 'book'. In one situation a language user encountering the word 'book' will fetch the material sense; in another situation, the abstract sense is fetched.

So far so good, perhaps, but the account has nothing to say about genuinely ad hoc lexical modulation. It is not plausible that the occasion-specific sense of 'upset' intended by Kato (example 4 above) was already extant for his hearers to fetch. Similarly for genuinely novel metaphors and genuinely novel cross-categorical cases. Nonetheless, speaker and hearer are - often enough somehow able to coordinate and understand each other in these cases too. ${ }^{16}$

\section{Going Beyond Non-Semantic Views}

The proposals discussed in the previous section are a step in the right direction. But they do not go far enough. In Barsalou and Rayo's proposals, concepts play no role in modulation, but they are compatible with (A5) and in fact endorse the core idea: we associate beliefs, stereotypes, multimodal memories and so on with a word. In lexical modulation some but not all of this encyclopaedic information is activated. The activated encyclopaedic information is the ad hoc concept. We think that even this tenet of the standard view should be given up. One reason became clear in the previous section: if the information activated is conceived of as representations, we must again ask whether they are occasion-specific or not. If they are, we have not made progress. But our main reason is that in important cases of modulations there is no information that can be activated to form an ad hoc concept.

First, suppose for the sake of argument that 'cut' encodes a concept of cutting. It is a mental address linked to a property and at this address encyclopaedic information about things having the property is stored. When you list the things you take to be widely held true about the activity of

\footnotetext{
${ }^{16}$ Cf. Bezuidenhout $(2002,107-9)$ who argues that occasion-sensitivity does not reduce to ambiguity or polysemy.
} 
cutting you will likely come up with a list like this:

done with scissors, a knife or something like it.

done to hair, hedges, cakes.

stereotypical types of cutting: cutting paper, cutting hair.

One can add further pictorial and auditory representations of cutting. However, on this list there is nothing about the length of time that the effect of cutting must last or whether something is only cut if it takes a further operation to join the results of the cutting back together. This is why some of the cases we considered have the surprising character they have. The example of the lightsabre as well as others make vivid both that there are facts we take for granted and that this is so in general only becomes recognisable in situations in which these facts no longer hold. We take these facts for granted by acting accordingly, but not because they are part of the encyclopaedic knowledge belonging to the concept of cutting, if there is one. Hence, while activation of encyclopaedic information often has a role in modulation, this is not always the case.

Second, consider a Travis case:

Pia's Japanese maple is full of russet leaves. Believing that green is the colour of leaves, she paints them. Returning, she reports, 'That's better. The leaves are green now.' She speaks truth. A botanist friend then phones, seeking green leaves for the study of green-leaf chemistry. 'The leaves (on my tree) are green,' Pia says. 'You can have those.' But now Pia speaks falsehood. (Travis 1997, 89)

Assuming that Travis' intuitions are right, Pia's different uses of 'green' express different ad hoc concepts ${ }^{17}$. But neither imagining nor recalling green things in general nor green leaves in particular nor the encyclopaedic information attached to our green concept (if any) will result in the expression of the ad hoc concept understood by the botanist. Again a tacit assumption is in play, namely, roughly speaking, that leaves are green in virtue of a biological process.

\footnotetext{
${ }^{17}$ The example is underdescribed. Is Pia trying to use 'green' in the same sense as before? If so, there is miscommunication. Or perhaps she realizes what the botanist wants to know but decides to mislead him. However, the questions raised about the roles played by context, speaker intentions and (speaker beliefs about) hearer expectations in determining the concept expressed are, we assume, orthogonal to our concerns here.
} 
Our argument here is related to Searle's $(1978 ; 1980)$ notion of the 'background' ${ }^{18}$ Encyclopaedic knowledge - by definition - is mentally represented. But as he pointed out, many things that are taken for granted in the use of words are not represented. Our examples show that lexical modulation can turn on revision of these hitherto entirely tacit assumptions. If that is right, then it casts serious doubt on assumption (A5) and any account of lexical modulation as the construction of an ad hoc concept from activated mentally represented information.

Now this notion of 'tacit' assumption needs further clarification. Searle's notion of background is a first port of call, but not more. The background 'is a set of nonrepresentational mental capacities that enable all representation to take place' (Searle 1983, 143). We agree with the main contention, but Searle seems only to label a problem. For how do non-representational mental capacities enable representation? Searle has mainly dispositions and stances in mind. I am disposed to expect that a cut makes a lasting separation of parts. But this disposition is the disposition to form representations. Which mental dispositions are non-representational and yet ground and determine the truth-conditions of our representations?

We will therefore approach the notion of tacit belief differently. Sometimes our beliefs are manifest in the ways we act. For example, my belief that the ice is thin is manifest in the ways in which I skate. (Ryle 1949, 134-5.) Assent to a sentence is just one such way of acting; it is a convenient way to identify beliefs and their contents. But we need a broader notion of belief to explain the behaviour of non-linguistic animals. Barcan Marcus has developed an account of this notion of belief, the object-centred account of belief. Her object-centred account of belief identifies belief with a differential disposition to a state of affairs:

$\mathrm{x}$ believes that $\mathrm{S}$ just in case, under certain agent-centered circumstances including $\mathrm{x}$ 's desires and needs as well as external circumstances, $\mathrm{x}$ is disposed to act as if $\mathrm{S}$, that actual or nonactual state of affairs, obtains. (Barcan Marcus 1990, 241)

Believing that so-and-so does not require concept possession. For example, believing that the sun is shining is a differential disposition to the state of affairs of the sun's shining, however described or presented. Similarly for the belief that unsupported objects fall. A belief may be grounded in mental representations, but it may also be a brute disposition, whether innate, acquired by exposure to environmental stimuli, or some combination of the two.

Now when we apply words we are disposed to act in certain ways without ever having reflected on or articulated these dispositions. If something has been cut, we are disposed to act as if the separation

\footnotetext{
${ }^{18}$ See also Recanati 2004, sections 9.4 and 9.5, on implicit features and hidden background. We build on these observations in our argument.
} 
was one which could only be undone by special effort. If we apply 'green' to plants we are disposed to make inferences that take for granted that there is some cause of the colour inherent to the plant, and probably to act as if the life of the plant is still ongoing and so on ${ }^{19}$. These dispositions are the tacit assumptions that we make. Normally, we only realise that we make them when we are confronted with cases in which they do not hold.

Here is an indirect illustration. (See Parfit 1984, 200f.) Imagine that science finally gets round to inventing a machine that scans you, makes a blueprint, destroys you and sends the blueprint through space to a distant planet where a physical replica is made. Have you travelled to the distant planet? Is the replica you? There are no answers to these questions that flow from our understanding of 'human being' or 'person'. Why?

To seek what is 'logically required' for sameness of person under unprecedented circumstances is to suggest that words have some logical force beyond what our past needs have invested them with. (Quine 1972, 490; quoted in Parfit 1984, 200; our emphasis)

We acquired the use of 'person' taking unthinkingly for granted certain conditions. However, we are neither able to enumerate nor fully specify these circumstances (cf. Searle's 'background'). What we take for granted in using 'person' is that things are relevantly similar now to the situation in which 'person' was established and used before, without being able to list all that we take for granted. In the situation described above we find out that some of the circumstances we took for granted are not met. For example, our actions towards a person manifest the assumption that people don't divide or branch. When I meet with you my behaviour never reflects the possibility that it is 'another' you.

Let us explore this idea further. The conditions we take for granted are states of affairs, for example facts about gravitational forces or available technology. We don't represent these states of affairs when we use an expression and no problems arise for that use. We simply take unthinkingly for granted that the relevant facts, whatever they are, obtain.

When it comes to lexical modulation two kinds of facts are especially important:

First, facts about the way in which something possesses a property which were taken for granted in the acquisition of the general term need not hold on the occasion of use. For example, you may have acquired the use of 'green' from uses that applied the word to fruits and vegetables that are green in virtue of performing or having performed photosynthesis. When you apply 'green' to an object of these kinds you will then take for granted that the colour has a natural source, without considering examples like the one Travis made us aware of.

\footnotetext{
${ }^{19}$ Cf. Keil's (1989) work on the assumptions built into taking a kind to be animate, or artefactual.
} 
Something similar applies to verbs like 'cut'. Consider examples (6 and 7) again. The fact that the examples are surprising and provoke thought suggests that we took for granted that cutting effects by means of a sharp edged instrument a separation of parts that is not 'self-healing'. It never occurs to us that this might not be so. In the example of the lightsabre an advance in technology brought it about that one condition we took for granted is no longer in place. Hence, we need to express a new occasion-specific meaning of 'to cut'.

Second, facts about the relation between observable similarities and kinds. For example, we take for granted that animals that look and behave like us belong like us to the kind homo sapiens sapiens. But we never considered that animals that look and behave like us may not have originated from the same ancestors. Are rational animals that look exactly like us but have evolved on Alpha Centauri still human beings?

In sum: some cases of lexical modulation cannot be explained in terms of the activation of either concepts or encyclopaedic information. These can therefore not fully constitute an ad hoc concept. Yet in the cases we have been considering words have an occasion-specific meaning. How should we, then, think about lexical modulation and ad hoc concepts?

\section{Lexical Modulation and Causal Coordination}

Let's approach this question from a different direction. There are independent reasons to hold that, in general, shared understanding of a word does not consist in shared knowledge of meaning, whether the meaning is conceived as a concept or not. Consider the following argument:

There is no shared meaning of the name 'Hesperus' (referring to Venus) in English.

Therefore, shared understanding of utterances of 'Hesperus' (referring to Venus) does not consist in (require) shared knowledge of a standing meaning/concept.

Therefore: shared understanding of utterances of 'Hesperus' is a matter of social coordination.

Different people use 'Hesperus' on the basis of different conditions (broadly speaking) that an object must meet to be Hesperus. There is no procedure that allows one to privilege one set of conditions as those knowledge of which constitutes knowledge of meaning of 'Hesperus'. If there is no shared meaning of 'Hesperus', shared understanding cannot consist in knowledge of such a meaning.

In what does it consist? In general, what binds several different things, either at a time or over time, together into one unity are causal relations between them of a particular kind. ${ }^{20}$ So in the case of words. What makes different people at a time or over time use a word with the same meaning is that the uses of the word are suitably causally related. Plausibly, what we mean when we say that someone knows a word is that person has an ability that allows her to successfully carry out the intention to use

${ }^{20}$ See Williamson 2007, 123. 
it as other people, in particular, its originators, use or used it.

Note that practitioners need not decide or believe that they are following the same practice as others in order to participate in the same practice. They just need to actually do so. Sainsbury (2005, 117f) provides a plausible necessary condition for a practitioner to continue to participate in a practice of using a word: his use must be sensitive to the information from earlier uses in the same practice. For example, I don't count as continuing participation in the practice of using 'gold' if in applying the word I simply don't take notice of the information associated with previous uses. I may not endorse the information associated with previous uses because I have a radically different view of, for example, gold. But for my view to be still a view of gold I at least need to register and reject some of the encyclopaedic information to count as continuing the practice. There need not be encyclopaedic information associated with 'gold' in the practice that all uses of 'gold' are sensitive to; it is sufficient that for every use of 'gold' there is some encyclopaedic information that the use is sensitive to.

We can use this necessary condition to bring out what is plausible and what is implausible about grab bags without collapsing the practice view into the grab bag view. The associated information may comprise 'items' of various kinds as the grab bag view has it. Sensitivity to this information is required for continued participation in a practice. But the information does not play the role of standing meaning. For there is not one body of information to which all uses are sensitive. The grab bag view is mistaken in holding that the body of information plays a role in lexical modulation. Sensitivity to this information is needed for participation in a practice, but does not help to explain lexical modulation.

A word has different uses if the uses can be traced back by the right causal route to different points of origin. ${ }^{21}$ For example, even if the encounter with the same substance had led different people to come up with the same general term ' $F$ ' completely independently we have still two different uses of the same phonetic/syntactic word with the same referent. Why? Because they cannot communicate by using ' $\mathrm{F}$ ' without introducing each other to their uses.

The intuitions about reference that support the causal/historical theory of reference pioneered by Kripke (1980) and Putnam (1975) also confirm the proposed view of shared understanding. ${ }^{22}$ In this view the notion of meaning is only used to register the right kind of causal coordination between speakers. The word can be used with the same meaning because speakers are correctly aligned, not because the word has the same meaning. This suggests the view that linguistic competence with a word consists in being properly aligned with other users of the word:

The measure of full understanding is not possession of a full set of metaphysically necessary truths but complete induction into a practice. (Williamson 2000, 211)

\footnotetext{
${ }^{21}$ See Sainsbury 2005, 3.6 who develops this idea in detail for uses of proper names.

${ }^{22}$ See also Evans (1982) and Kaplan (1990).
} 
We take this picture of knowledge of meaning to generalize to all words apart from those whose meaning is determined by inference rules, if there are any.

The causal integration model of linguistic competence supports and helps to explain cases of lexical modulation that don't involve activation of encyclopaedic information by appealing to the intention to use a word as others do. If a speaker applies 'green' to something that is uniformly blue on both the inside and outside, her intention to conform her use of 'green' to ours and that of past users is defeated by her communicative intention ${ }^{23}$. However, there are cases that are similar enough to the original use so that they don't undermine the assumption that the speaker intends to conform to prior usage. Pia's case is one. Pia says 'These leaves are green' pointing to leaves she painted green, intending to conform to past use. On the one hand, we want to see Pia as using the word 'green' in conformity with previous uses of the word. On the other hand, we want to engage in communication on this particular occasion with Pia. Suppose that in the prior usage of 'green' in application to leaves you have been exposed to, 'green' was only applied to leaves whose greenness was a result of ongoing photosynthesis. If we encounter an application of 'green' to an object that is green for some other reason, we can see the speaker either (a) as conforming to the original usage of 'green' but inviting me to revise what I took for granted, namely facts about how objects have this property or (b) introducing a new use of 'green' (the speaker wants to create, rather than to conform). Option (a) allows the speaker to say something true about a subject matter and not to talk past you. Hence, (a) is preferable to (b) according to which the speaker endows 'green' with a new meaning. For this reason we speak of modulation of the meaning of a word and not of creation of a new meaning or a case of ambiguity. The audience could put their response as follows: the leaves are green (and the speaker conforms to prior usage) although I previously took for granted that when a plant is green that is an intrinsic property of the plant. But why should I restrict the use of 'green' in this way? The causal source of the colour of an object need not prevent me from seeing the colourwise similarity between the colour of the leaves and, say, the colour of a piece of jade.

If I no longer take the fact about the cause of the colour for granted, accepting the utterance of, say, 'These leaves are green' will result in a shift in inferential dispositions and dispositions to act. In general, if we accept what a specific utterance says then we have occasion-specific inferential dispositions. ${ }^{24}$ Consider now a speaker who realises what the biologist is interested in, and says to him 'The leaves of this plant are green'. If he appreciates the speaker's communicative intention and her

\footnotetext{
${ }^{23}$ Her communicative intention could be satisfied in various ways: e.g. she may be able to successfully communicate using 'green' loosely or metaphorically, depending on the circumstances. ${ }^{24}$ There are different ways to think about these inferential dispositions. Corsentino $(2012,541)$ talks about perspectives on properties as cognitive dispositions, that is dispositions to make inferences on particular occasions.
} 
conformity intention, he will now be primed to infer that the plant demonstrated is green intrinsically (rather than extrinsically) and act accordingly.

Note that we are not claiming that talk of practices fully explains the abilities that language users possess. It is obviously desirable to say in addition as much as possible about the cognitive equipment that underlies and makes possible the acquisition and use of such lexical competences. (See the next section for some suggestions.) We do think that theorising about linguistic meaning needs to pay more attention to the variety and specificity of usage ${ }^{25}$.

A good example of the complexity of actual usage is modulation across syntactic categories. Consider again cases like 'porch' and 'wrist' used as verbs. Here, too, consideration of the intentions of the speaker is helpful. In such cases none of the intentions wins. For on the one hand we do want to see the speaker as conforming to past uses of a word or word fragment: the similarity of the new verb 'porch' and the noun 'porch' is not accidental. The speaker used 'porch' as a verb because there is already a practice of using the noun 'porch'. But on the other hand his manifest intention to speak about an activity, which can be inferred (non-demonstratively) from the syntactic parse of the sentence, forces us to see him as deviating from the original practice of use. We have here then a hybrid use that conforms as well as deviates. The theory proposed has room for such cases and this is an advantage. We don't need to assume in such cases of cross-category modulation either ambiguities or 'amorphous' concepts and properties.

When there are already two related words of different categories, such as the noun and verb pairs 'fly' and 'flight', or 'stop' and 'stop', the situation is more complex still. Here a fully competent speaker has two related but distinct abilities.

Let us take stock of our proposal so far. It might be thought that a theory which dispenses with the assumption (A2) that standing meanings of words are extension-determining concepts must lack the resources to distinguish neologisms from conventional uses, since it cannot claim that conventional uses are just those in which the concept expressed is equal to the concept encoded. This may be a problem for some such theories. It is a strength of our theory that it has an account of this distinction (in terms of speaker intentions).

A further distinction that might seem to be lost by a theory that denies A2 is that between literal and non-literal use, since (similarly) it cannot claim that literal uses are just those in which the concept expressed is equal to the concept encoded. We argue in the next section that the distinction

\footnotetext{
${ }^{25} \mathrm{We}$ would like to thank an anonymous referee for suggesting that this was what we should want to say.
} 
may be best understood instead in terms of I-analytic features. ${ }^{26}$

\section{I-Analyticity}

In case (a) above no new sense is introduced, although background assumptions are revised. On the other hand, novel cross-categorical uses necessarily introduce a new sense: there was no sense previously for 'porch' used as a verb. Now there are also cases of lexical modulation without category change that introduce new senses, or try to. To account for the contrast we will draw on the notion of I-analyticity.

Some linguists and philosophers have tried to develop a theory of I-analyticity, according to which some words encode necessary conditions that are part of one's linguistic competence. For example, they claim that one cannot be competent with the verb 'persuade' unless one grasps the link between 'persuade' and 'intend' such that literal utterances of sentences of the form "If $\mathrm{X}$ has persuaded $\mathrm{Y}$ to do Z then Y intends to do Z" (with X, Y, Z non-vacuously filled) are all true (Rey 2003/2013, §4.4, citing Chomsky). On this view, words have partial meanings: for each word there is a list of necessary but in general not jointly sufficient conditions (Chomsky 1975, 233 fn. 13; 1977, 142; Moravcsik, 1981, 1998; Laurence \& Margolis 1999, 52) ${ }^{27}$. This view is popular in linguistic lexical semantics (e.g. Pinker, 1989; Jackendoff, 1990; Levin \& Rappaport Hovav, 1995, 2005); one reason is that there is independent evidence for some postulated semantic features from their role in licensing syntactic alternations (Leben, 2015). If there are such I-analytic facts, then what it takes to know a word includes being competent in the word's I-analytic entailments.

This provides a natural characterisation of some cases which attempt to introduce a new sense. If 'persuade' I-entails 'intend' in the I-languages of speaker and hearer, but the speaker uses (or tries to use) 'persuade' in a different way, then she is attempting to introduce a new sense for the word, either to replace the existing sense or to stand alongside it (creating lexical ambiguity). Contrast this with novel utterances of sentences with 'cut' in $(5 \mathrm{a}-\mathrm{d})$. These can be seen as using the existing resources of the language in a way that had not previously occurred to its speakers. And contrast that with the

\footnotetext{
${ }^{26} \mathrm{We}$ owe thanks to an anonymous referee for pointing out that we had in effect answered these objections but had not explained that we were doing so.

${ }^{27}$ There are two different versions of these theories (Leben, 2015). According to the first, the components of word meanings are themselves words (Lakoff, 1965; McCawley, 1968; Wierzbicka, 1996). According to the second variant the components are not words (e.g. Glanzberg, 2011): this is the line usually taken in neoclassical lexical semantics (Laurence \& Margolis 1999, §5). For a similar proposal coming from a very different tradition, see Sainsbury $(2006,253)$ on the givenness and specificity features of 'the'.
} 
initial use of (5e) 'cut taxes' which presumably dropped I-analytic features - nothing is separated from anything when taxes are cut - and eventually led to the lexicalisation of a new sense. ${ }^{28}$

Equally, if there are I-analytic features, then these provide a way, consistent with our main proposal, to distinguish metaphorical cases from literal uses. The speaker who first used 'green' metaphorically in the description of a naïve or innocent person was using it in a way that drops what is (let us suppose) one of the I-analytic features of 'green', namely coloured. However she does not propose that this feature is dropped for all future utterances of the form 'green'. She initially proposes only that it is suspended for that very use. (But that use may catch on, and eventually become lexicalised.) Similarly, novel uses of (5e) 'cut taxes' were metaphorical. Of course, once the new sense of 'cut' has become established, uses of 'cut taxes' are literal uses of that new sense. Again contrast this with the various uses of 'cut' in ( $5 \mathrm{a}-\mathrm{d})$, and with 'green' used for leaves that have been painted green or objects that are green on the inside. No I-analytic feature (we suppose) has to be suspended in these cases. We can say that they are all literal uses, while uses that suspend an Ianalytic feature are metaphorical ones.

Our intuitions may be less clear about some cases, such as uses like 'cut with a lightsabre' where (we have suggested) a necessary feature, 'EDGED' in this case, is operative but understood atypically. Our perplexity fits well with this model: this is neither a prototypical literal use nor a prototypical metaphorical use.

\section{Conclusion}

We hope to have given reasons to reject the main tenets of the standard theory of lexical modulation as well as modifications of the theory. There are 'deep' cases of lexical modulation that concern neither concepts, whether atomic or complex, nor encyclopaedic information. On the basis of a causal-historical model of shared understanding we have given a description of such cases of lexical modulation. According to the proposal, one understands a word if, and only if, one is sufficiently inducted in the practice of using it. And one is so inducted if one can intend to conform to prior usage. All uses of a particular word with the intention to conform to past use are bound together by that

\footnotetext{
${ }^{28} \mathrm{We}$ do not attempt here answers to the notoriously difficult questions of what makes some uses catch on and become lexicalised, while others are ephemeral; or what decides whether a new sense supplants an existing one (e.g. example 13c, 'hound') or co-exists with it (e.g. 'green' used both for a colour and for naivety). An account might bring together work in historical linguistics on lexicalization and language change (e.g. Brinton \& Traugott, 2005; see also Traugott, 2012) with work on the interplay of cognitive and social processes in the spread of cultural practices, knowledge etc. (e.g. Sperber, 1996; Sperber \& Hirschfeld, 2004).
} 
intention and the history of use. Lexical modulation of a word puts into play a new sense when the intention of a speaker to conform to prior usage is in conflict with her communicative intention. In 'deep' lexical modulation this conflict is plausibly resolved by abandoning one/some of the assumption(s) about the reference we have taken so far for granted.

The causal-historical model also covers cases in which, plausibly, encyclopaedic information is activated. For in many cases speakers who are causally integrated with others will have similar beliefs/encyclopaedic information ready to be activated. But the model proposed is more general and therefore preferable, we think. We have also shown that I-analytic features (if they exist) may be retained in lexical modulation (as in literal use) or dropped, or retained but understood in a new way.

In the cases we discussed, lexical modulation looks like a widening or narrowing of the extension. For example, one might say that in the Travis examples the extension of 'green' seems, relative to previous uses of the word, to have been widened to leaves that have been painted green or to objects that are green on the inside. This is a welcome consequence as we can explain why the broadening description seems plausible even though there is no concept that is the word's standing meaning.

What about cases that have been described as 'narrowing'? Consider the examples in (13):

(13) a. Churchill was a man.

b. Buying a house is easy if you've got money. (both Wilson \& Carston 2007, 232)

c. Old English 'hund' $(\operatorname{dog})>$ Modern English 'hound' (a specific type of dog)

In cases like (13a) and (13b), and in the novel uses that led to the lexical change in (13c), the hearer has to/had to infer from the context that the speaker intended some restriction that does not exist in the general use of the word. Thus the concept expressed on that occasion may have a narrower extension than the concepts expressed by average or stereotypical uses of the word. Again, we can see why the narrowing description seems plausible without needing to postulate any concept that the word encodes. ${ }^{29}$

${ }^{29}$ We presented predecessors of this work at the Polysemy Workshop at the University of the Basque Country in Vitoria Gasteiz in 2012, and in 2014 at the Research Seminar for Language and Cognition, King's College London, the Colloquium of the Center for the Study of Mind and Nature, and the conference 'Word Meaning' at Cumberland Lodge, and in 2016 at the University of Maryland College Park Linguistics and Philosophy Colloquium. We thank all audiences for feedback and discussion. Thanks in particular to Robyn Carston, Alison Hall, Michael McCourt, Georges Rey, Charles Travis, and Agustín Vicente. Special thanks to Steven Gross and to Carlo Penco for written 


\section{REFERENCES}

Allott, N. 2013, "Relevance Theory", in: A. Capone, F. Lo Piparo and M. Carapezza, eds., Perspectives on Linguistic Pragmatics, Heidelberg: Springer, pp. 57-98

Allott, N. and Textor, M. 2012, "Lexical Pragmatic Adjustment and Ad Hoc Concepts", International Review of Pragmatics 4(2), pp. 185-208

BARSALOU, L.W. 2005, “Situated Conceptualisation”, in: H. Cohen and C. Levebre, eds., Handbook of Categorisation in Cognitive Science, Amsterdam: Elsevier, pp. 619-650

Barsalou, L.W., SAntos, A., Simmons, W.K. and WiLSON, C.D. 2008, "Language and Simulation in Conceptual Processing", in: M. De Vega, A.M. Glenberg and A.C. Graesser, eds., Symbols, Embodiment, and Meaning, Oxford: Oxford University Press, pp. 245-283

BarCan MARCuS, R. 1990, “Some Revisionary Proposals about Belief and Believing”, Philosophy and Phenomenological Research 50, pp. 133-53

BeZuidenhout, A. 2002, "Truth-Conditional Pragmatics”, Noûs 36, pp. 105-134

BRinton, L. J. and TraugotT, E. C. 2005, Lexicalization and Language Change, Cambridge: Cambridge University Press

CARStOn, R. 1997, "Enrichment and Loosening: Complementary Processes in Deriving the Proposition Expressed", Linguistische Berichte 8, pp. 103-127

CARston, R. 2002a, "Linguistic Meaning, Communicated Meaning and Cognitive Pragmatics", Mind \& Language 17(1\&2), pp. 127-148

CARSTON, R. 2002b, Thoughts and Utterances: The Pragmatics of Explicit Communication, Oxford: Blackwell

CARston, R. 2010, “Explicit Communication and 'Free' Pragmatic Enrichment”, in: B. Soria and E. Romero, eds., Explicit Communication: Robyn Carston's Pragmatics, Basingstoke: Palgrave Macmillan, pp. 217-285

CARSTON, R. 2012, "Word meaning and Concept Expressed”, The Linguistic Review 29(4), pp. 607-

comments and to Peter Sutton for criticism which effected substantial changes. We would also like to thank the anonymous referees for their comments and suggestions. Nicholas Allott: This paper was written with the support of the Research Council of Norway, as part of project 213068, 'The Reflective Mind', for which I am very grateful. Mark Textor: The paper was written with the support of the AHRC Grant AH/1000216/1 (Word-Meaning: what it is and what it is not). I am grateful for the support. 
623

Chomsky, N. 1975, Reflections on Language, New York: Pantheon Books

CHOMsKy, N. 1977, Essays on Form and Interpretation, New York: North-Holland

Chomsky, N. 2000, New Horizons in the Study of Language and Mind, Cambridge: Cambridge University Press

CoHEN, L. J. 1971, "Some Remarks on Grice's Views about the Logical Particles of Natural Language”, in: Y. Bar-Hillel, ed., Pragmatics of Natural Languages, New York: Humanities Press, pp. 50-68

COLLINS, J. 2007, “Syntax, More or Less”, Mind 116(464), pp. 805-850

Corsentino, A. 2012, "Predicates in Perspective”, Synthese 187(2), pp. 519-545

Evans, G. 1982, The Varieties of Reference, Oxford: Clarendon Press

Fodor, J. A., Garrett, M. F., Walker, E. C. T. and PArKes, C. H. 1980, “Against Definitions”, Cognition 8(3), pp. 263-367

FODOR, J. A. 1998, Concepts. Where Cognitive Science Went Wrong, Oxford: Oxford University Press

GLAnzBerg, M. 2011, “Meaning, Concepts, and the Lexicon”, Croatian Journal of Philosophy 11, pp. 1-29

HANSEN, N. 2011, “Color adjectives and Radical Contextualism”, Linguistics and Philosophy 34(3), pp. 201-221

Huddleston, R. D. and Pullum, G. K. 2002, The Cambridge Grammar of the English Language, Cambridge: Cambridge University Press

JACKENDOFF, R. 1990, Semantic Structures, Cambridge, Mass.: MIT Press

KAPLAN, D. 1990, “Words", Proceedings of the Aristotelian Society, Supplementary Volumes 64, pp. 93-119.

KeIL, F. C. 1989, Concepts, Kinds, and Cognitive Development, Cambridge, Mass.: MIT Press

KenNedy, C. and MCNALly, L. 2010, "Color, Context, and Compositionality”, Synthese 174(1), pp. 79-98

Korta, K. and Perry, J. 2006, "Pragmatics”, in: E. N. Zalta, ed., The Stanford Encyclopedia of Philosophy. (Summer 2006 ed.).

KRIPKE, S. A. 1980, Naming and Necessity, Oxford: Blackwell

LAKOFF, G. 1965, On the Nature of Syntactic Irregularity, PhD thesis, Harvard University 
Laurence, S. and Margolis, E. 1999, "Concepts and Cognitive Science”, in: E. Margolis and S. Laurence, eds., Concepts: Core Readings, Cambridge, Mass.: MIT Press, pp. 3-82

LEBEN, D. 2015, “Neoclassical Concepts”, Mind \& Language, 30(1), pp. 44-69

Levin, B. and RAPPAPORT Hovav, M. 1995, Unaccusativity: At the Syntax-Lexical Semantics Interface, Cambridge, Mass.: MIT Press

Levin, B. and RaPPAPORT Hovav, M. 2005, Argument Realization, Cambridge: Cambridge University Press

LyONS, J. 1977, Semantics, Cambridge: Cambridge University Press

MCCAWLEY, J. D. 1968, “The Role of Semantics in a Grammar”, in: E. W. Bach and R. T. Harms, eds., Universals in Linguistic Theory, New York: Holt, Rinehart and Winston, pp. 124-169

MoRAVCSIK, J. M. E. 1981, “How do Words Get Their Meanings?”, The Journal of Philosophy, 78(1), pp. 5-24

MoravcsiK, J. M. E. 1998, Meaning, Creativity, and the Partial Inscrutability of the Human Mind, Stanford, Calif.: CSLI Publications

PARFIT, D. 1984, Reasons and Persons, Oxford: Clarendon Press

Pietroski, P. M. 2010, “Concepts, Meanings and Truth: First Nature, Second Nature and Hard Work", Mind and Language 25(3), pp. 247-278

Pietroski, P. M. 2017, “Semantic Internalism”, in: J. McGilvray, ed., The Cambridge Companion to Chomsky, (2nd ed.) Cambridge: Cambridge University Press, pp. 196-216

PINKER, S. 1989, Learnability and Cognition: The Acquisition of Argument Structure, Cambridge, Mass.: MIT Press

PUlluM, G. K. 2013, “Being a Preposition”, Lingua Franca (Blog at The Chronicle of Higher Education webpage) Retrieved 26 April 2017, http://www.chronicle.com/blogs/linguafranca/2013/02/05/being-a-preposition/

PutnAM, H. 1975, “The Meaning of 'Meaning'”, in: K. Gunderson, ed., Language, Mind, and Knowledge, Minneapolis: University of Minnesota Press, pp. 131-193

QuINE, W. V. 1972, Book review: Identity and Individuation. Munitz, Milton K., ed., The Journal of Philosophy, 69(16), 488-497.

RAYO, A. 2013, “A plea for semantic localism”, Noûs, 47(4), pp. 647-679

ReCanati, F. 1989, “The Pragmatics of What is Said”, Mind and Language 4, pp. 295-329

ReCANATI, F. 1993, Direct Reference : From Language to Thought, Oxford: Blackwell 
ReCANATI, F. 2004, Literal Meaning, Cambridge: Cambridge University Press

ReCAnati, F. 2012, “Compositionality, Semantic Flexibility and Context-dependence”, in: W.

Hinzen, E. Machery and M. Werning, eds., The Oxford Handbook of Compositionality, Oxford: Oxford University Press, pp. 175-192

REY, G. 2003/2013, “The Analytic/Synthetic Distinction”, in: E. N. Zalta, ed., Stanford Encyclopedia of Philosophy. Available at http://plato.stanford.edu/entries/analytic-synthetic/

RothschiLd, D. AND Segal, G. 2009, “Indexical Predicates”, Mind \& Language, 24(4), pp. 467-493

RYLE, G. 1949, The Concept of Mind, London: Hutchinson

SAINSBURY, R. M. 2005, Reference Without Referents, Oxford: Clarendon Press

SAINSBURY, R. M. 2006, “Understanding as Immersion”, Philosophical Perspectives, 16(1), pp.246262

SEARLE, J. R. 1978, “Literal Meaning”, Erkenntnis, 13(1), pp. 207-224

SEARLE, J. R. 1980, “The Background of Meaning”, in: J. R. Searle, F. Kiefer and M. Bierwisch, eds., Speech Act Theory and Pragmatics, Dordrecht: Springer, pp. 221-232

SEARLE, J. R. 1983, Intentionality, Cambridge: Cambridge University Press

SPERBER, D. 1996, Explaining Culture: A Naturalistic Approach, Oxford: Blackwell

SPERBER, D. AND HIRSCHFELD, L. A. 2004, “The Cognitive Foundations of Cultural Stability and Diversity", Trends in Cognitive Sciences 8(1), pp. 40-46

SPERBER, D. AND Wilson, D. 1986, Relevance: Communication and Cognition (2nd ed. 1995), Oxford: Blackwell

SPERBER, D. AND WILSON, D. 1998, "The Mapping Between the Mental and the Public Lexicon", in:

P. Carruthers and J. Boucher, eds., Language and Thought: Interdisciplinary Themes, Cambridge: Cambridge University Press, pp. 184-200

SPERBER, D. AND WILSON, D. 2002, "Pragmatics, Modularity and Mind-reading", Mind \& Language 17(1\&2), pp. 3-23

Stanley, J. 2000, “Context and Logical Form”, Linguistics and Philosophy 23(4), pp. 391-434

SzABÓ, Z. G. 2001, “Adjectives in Context”, in: R. Harnish and I. Kenesei, eds., Perspectives on Semantics, Pragmatics, and Discourse, Amsterdam: John Benjamins, pp. 119-146

Travis, C. 1997, "Pragmatics", in: B. Hale and C. Wright, eds., A Companion to the Philosophy of Language, Oxford: Blackwell, pp. 87-107

TRAVIS, C. 2000, Unshadowed Thought: Representation in Thought and Language, Cambridge, Mass.: Harvard University Press 
Traugott, E. C. 2012, "Pragmatics and Language Change", in: K. Allan and K. Jaszczolt, eds., The Cambridge Handbook of Pragmatics, Cambridge: Cambridge University Press, pp. 549-565

Traugott, E. C. And Dasher, R. B. 2002, Regularity in Semantic Change, Cambridge: Cambridge University Press

TraugOtT, E. C. AND KÖNIG, E. 1991, “The Semantics-Pragmatics of Grammmaticalization revisited", in: E. C. Traugott and B. Heine, eds., Approaches to Grammaticalization, Amsterdam; Philadelphia: J. Benjamins, Vol. I, pp. 189-218

WierZBICKA, A. 1996, Semantics: Primes and Universals, Oxford: Oxford University Press WiLliamson, T. 2007, The Philosophy of Philosophy, Oxford: Blackwell

WiLson, D. AND CARSTON, R. 2007, “A Unitary Approach to Lexical Pragmatics: Relevance, Inference and Ad Hoc Concepts", in: N. Burton-Roberts, ed., Pragmatics, Basingstoke: Palgrave Macmillan, pp. 230-259

WILSON, D. AND SPERBER, D. 2002, “Truthfulness and Relevance”, Mind 111 (443), pp. 583-632 